\title{
ESTUDO DE SIMULAÇÃO DA INVERSÃO ÁGUA/ÓLEO COM A UTILIZAÇÃO DO MÉTODO LEVEL SET
}

\author{
D. P. TRAMONTIN ${ }^{1}$, C. S. GONÇALVES ${ }^{1}$, F. MIOTTO ${ }^{1}$, M. B. QUADRI ${ }^{1}$ \\ ${ }^{1}$ Universidade Federal de Santa Catarina, Departamento de Engenharia Química e \\ Engenharia de Alimentos \\ E-mail para contato: deiseparol@gmail.com
}

\begin{abstract}
RESUMO - O Brasil possui grandes reservas de petróleo offshore, por isso se fazem necessários estudos envolvendo as propriedades e padrões de escoamento de sistemas água/óleo comuns nas operações de produção, mas também de grande interesse nas situações de vazamento e resgate de óleo em caso de acidente. Este estudo visa simular o deslocamento do óleo a partir da água com o auxílio do software COMSOL Multiphysics ${ }^{\circledR} 4.3 \mathrm{~b}$, onde são considerados aspectos operacionais como a geometria do sistema, além de propriedades como: tensão interfacial, densidades e viscosidades. Os resultados obtidos para esse tipo de escoamento imiscível mostraram-se fisicamente coerentes e adequados frente a outros trabalhos encontrados na literatura e, portanto, atestam a viabilidade da abordagem adotada no presente estudo.
\end{abstract}

\section{INTRODUÇÃOO}

Com a crescente demanda de energia no Brasil e no mundo, as recentes descobertas de petróleo em águas profundas e a falta de uma tecnologia ou matéria prima disponível que possa substituir em grande parte o uso do petróleo, nos fazem perceber que a extração continuará existindo e tende a um aumento considerável nas operações de exploração offshore.

Diante do panorama apresentado é visto que nos próximos anos uma grande quantidade de dutos submarinos deverá ser instalada, juntamente com postos de operações e isto faz com que o risco de vazamentos aumente embora se tenha elevados padrões de segurança envolvidos.

No caso do vazamento de em dutos submersos, o óleo tende a vazar pelo orifício subindo para superfície devido à diferença de densidades dos fluidos. Considerando o princípio da conservação da massa, a água que se encontra externa ao duto tende a penetrar no interior do mesmo ocupando o espaço deixado pelo óleo. Esse processo, cuja força motriz é de natureza gravitacional e que envolve simultaneamente a saída de óleo e entrada de água, é conhecido por migração advectiva (Baptista et al., 2007).

A injeção de água para a recuperação de óleo pode ocorrer com o objetivo de assegurar a manutenção da pressão no reservatório, de modo que desloque o óleo existente no poço de injeção em direção aos poços produtores. A água possui menor viscosidade comparada ao óleo e quando injetada desloca-se completamente, tomando caminhos preferenciais para os reservatórios produtores formando canais no seio da fase óleo. Estes canais resultam em 
produção excessiva de água e baixa eficiência na recuperação do óleo (Correia, 2009).

O derramamento de óleo resulta em um passivo ambiental de grandes proporções. Neste caso, faz-se necessário uma estimativa precisa do montante de óleo liberado para uma previsão do potencial impacto ambiental gerado (Oliveira, 2008).

Outro quesito importante que relaciona o escoamento imiscível água/óleo, a partir da perspectiva industrial e prática, são os fluxos volumétricos de dois fluidos, esta informação pode ser usada para quantificar a proporção ótima de água a ser injetada para minimizar os requisitos energéticos e o transporte de petróleo em dutos (Lawrence; Hewitt, 2001).

Este trabalho consiste em estudar e avaliar o deslocamento de óleo submerso através da ação da água, avaliando a fluidodinâmica do sistema, já que se trata de fluidos de diferentes propriedades. Para o estudo de simulação numérica do sistema, utilizou-se o software COMSOL Multiphysics $4.3 \mathrm{~b}$, no intuito de estudar as propriedades e características do sistema em questão.

\section{ASPECTOS FENOMENOLÓGICOS DO SISTEMA ÁGUA/ÓLEO}

As principais propriedades físicas consideradas no estudo do sistema água/óleo foram densidade, viscosidade, e a tensão interfacial dos líquidos, que serão brevemente explanadas em sua essência para que o seu entendimento facilite a previsão do comportamento do sistema em meio subaquático.

A água e o óleo formam um sistema bifásico líquido-líquido, heterogêneo e imiscível, que apresenta entre elas uma fronteira chamada de interface, que define a região de separação entre as duas fases e que pode apresentar-se bem definida contendo espessura de milímetros ou alguns micra, ou ainda apresentar-se conexa ou desconexa ou ambos os casos (Mariano, 2008).

A diferença de densidades entre a água e o óleo é a principal promotora do deslocamento das fases na ausência de forças externas (excetuando-se a força gravitacional) ou gradientes de pressão dinâmica.

A movimentação ou distribuição de um fluido é ocasionada pela tensão de cisalhamento, esta propriedade é definida como a força necessária para causar o movimento de uma camada do fluido. Quanto maior a viscosidade de um fluido, maior é o cisalhamento necessário para movimentá-lo, e tal viscosidade é dependente da velocidade da transferência da quantidade de momento molecular e da coesão, sendo esta última diretamente proporcional à viscosidade e inversamente proporcional à temperatura (Fox; Mc Donald, 1992, apud Feller, 2012).

A tensão superficial é o mais importante parâmetro na descrição de fenômenos interfaciais e é definida como a quantidade mínima de trabalho necessário para aumentar a área interfacial em uma unidade de área. A tensão interfacial, em misturas água/óleo, é o principal fator na imiscibilidade dos fluidos (Santos, 2003).

Para a análise do sistema em estudo, utilizou-se temperatura de $20^{\circ} \mathrm{C}$ e pressão 
atmosférica, deve-se levar em consideração que as propriedades dos fluidos foram tomadas nessas condições e que podem variar de acordo com a alteração das características do sistema.

\section{MATERIAIS E MÉTODOS}

\subsection{Procedimento Experimental}

Para a observação do comportamento experimental e posterior comparação com os resultados do modelo computacional, para fins de validação, fez-se necessário conceber um sistema de vazamento submerso de óleo em água. Para isso, um pequeno frasco com óleo e um recipiente maior com água destilada foram utilizados.

O recipiente de vidro com diâmetro de $17 \mathrm{~cm}$ foi preenchido com água destilada na altura de 21,5 cm. O frasco com dimensões de $6,2 \mathrm{~cm}$ de altura e $2,9 \mathrm{~cm}$ de diâmetro recebeu em seu interior óleo lubrificante de máquinas Spindura acrescido de uma pequena quantidade de tinta base óleo na cor azul (Acrilex), para promover uma melhor visualização do escoamento do óleo. Depois de imergir o frasco no recipiente com água destilada, retirou-se a sua tampa com a menor perturbação possível de modo a se promover o deslocamento do óleo pela água. A Tabela 1 apresenta as propriedades físicas de ambos os fluidos obtidos mediante análises laboratoriais.

Tabela 1 - Propriedades físicas dos fluidos

\begin{tabular}{|c|c|c|}
\hline Fluidos & Densidade $\left(\mathbf{K g} / \mathbf{m}^{\mathbf{3}}\right)$ & Viscosidade (Pa.s) \\
\hline Água destilada & 998 & 0,0010 \\
\hline Óleo Spindura & 830 & 0,0175 \\
\hline
\end{tabular}

O valor de tensão interfacial água destilada/óleo Spindura adotado foi 0,03291 N/m. A Figura 1 apresenta o decorrer do experimento de deslocamento do óleo através da água, onde ocorreu um gotejamento contínuo. Durante o experimento houve deslocamento aproximado de $59 \mathrm{~cm}^{3}$ de óleo em 19 segundos.

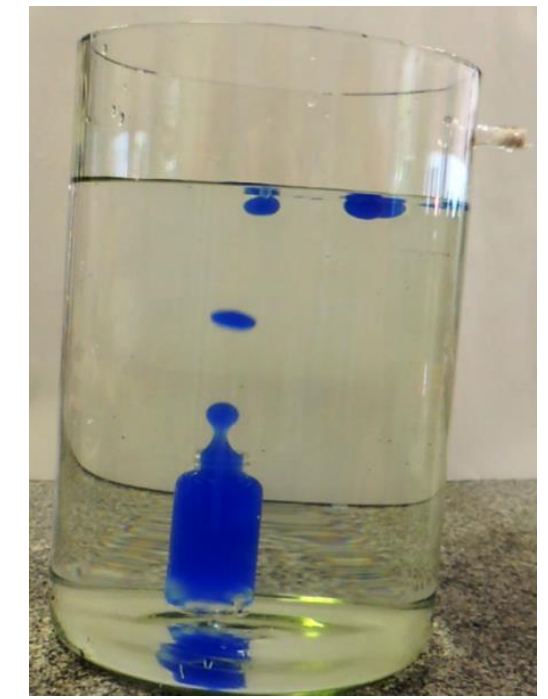

Figura 1 - Situação experimental. 
O gotejamento não ocorreu imediatamente após a abertura do frasco, passando-se aproximadamente $4 \mathrm{~s}$, tempo a partir do qual se verificou o desprendimento contínuo de gotas logo acima da borda do frasco. Esse comportamento se manteve até cessar o deslocamento do óleo, permanecendo ao final um volume não vazado de aproximadamente $20 \mathrm{~cm}^{3}$.

\subsection{Estudo Computacional}

Fluidodinâmica Computacional (CFD) é o termo dado ao grupo de técnicas matemáticas, numéricas e computacionais para predizer os fenômenos físicos ou físicos químicos que ocorrem em escoamentos que podem ser relacionados com a ação e a interação de mecanismos envolvendo fatores como dissipação, difusão, convecção, superfícies escorregadias, condições de contorno e turbulência. No campo de escoamento de fluidos, onde se inclui problemas com superfície livre, esses fenômenos são governados pela equação de Navier-Stokes (Fontes et al., 2005 apud Mariano, 2008).

A discretização das equações diferenciais que regem o fenômeno é feita através da técnica dos elementos finitos. O método de acompanhamento da interface utilizado no modelo foi o Level Set, onde a interface é representada por um isocontorno de uma função global definida, a função Level Set $\varphi$. A interface é definida pelo isocontorno de 0.5 , onde o padrão da $\varphi$ é definida para ser uma função de distância deste isocontorno (COMSOL Multiphysics v. $4.3 \mathrm{~b}, 2014)$.

O mecanismo da advecção no modelo Level Set não é feito de modo conservativo, isto implica que a zona delimitada pelo conjunto de nível 0 não é conservada. O movimento é analisado por convecção dos níveis da função, com o campo de velocidade $u$. A Equação 1 é elementar e governa o sistema (Osher; Fedkiw, 2001; apud Feller, 2012).

$$
\frac{\partial \varphi}{\partial t}+u \cdot \nabla \varphi=0
$$

No COMSOL, o modelo Level Set usa um reinicializador, que conserva o método para descrever a convecção na interface entre fluídos, modificando a equação elementar de acordo com a Equação 2:

$$
\frac{\partial \varphi}{\partial t}+u \cdot \nabla \varphi=\chi \nabla \cdot\left(\xi \nabla \varphi-\varphi(1-\varphi) \frac{\nabla \varphi}{|\nabla \varphi|}\right)
$$

Os termos do lado esquerdo fornecem o movimento correto da interface, enquanto que os termos do lado direito são necessários para a estabilidade numérica. $O$ parâmetro $\xi$, determina a espessura da região onde a $\varphi$ varia de zero a um, e é tipicamente da mesma ordem que o tamanho dos elementos da malha. Pelo padrão, ̧ é constante dentro de cada domínio e é igual ao maior valor do tamanho da malha, dentro do domínio total. O parâmetro $\chi$ determina a quantidade de reinicializações ou estabilizações da variável $\varphi$ (COMSOL Multiphysics v. 4.3b, 2014).

Definição do modelo: A geometria foi construída com base no modelo experimental, a 
fim de se obter resultados de simulação para fins de comparação. Na Figura 2 apresenta-se a geometria dos domínios ( 1 e 2) e as condições de contorno aplicadas para a simulação.

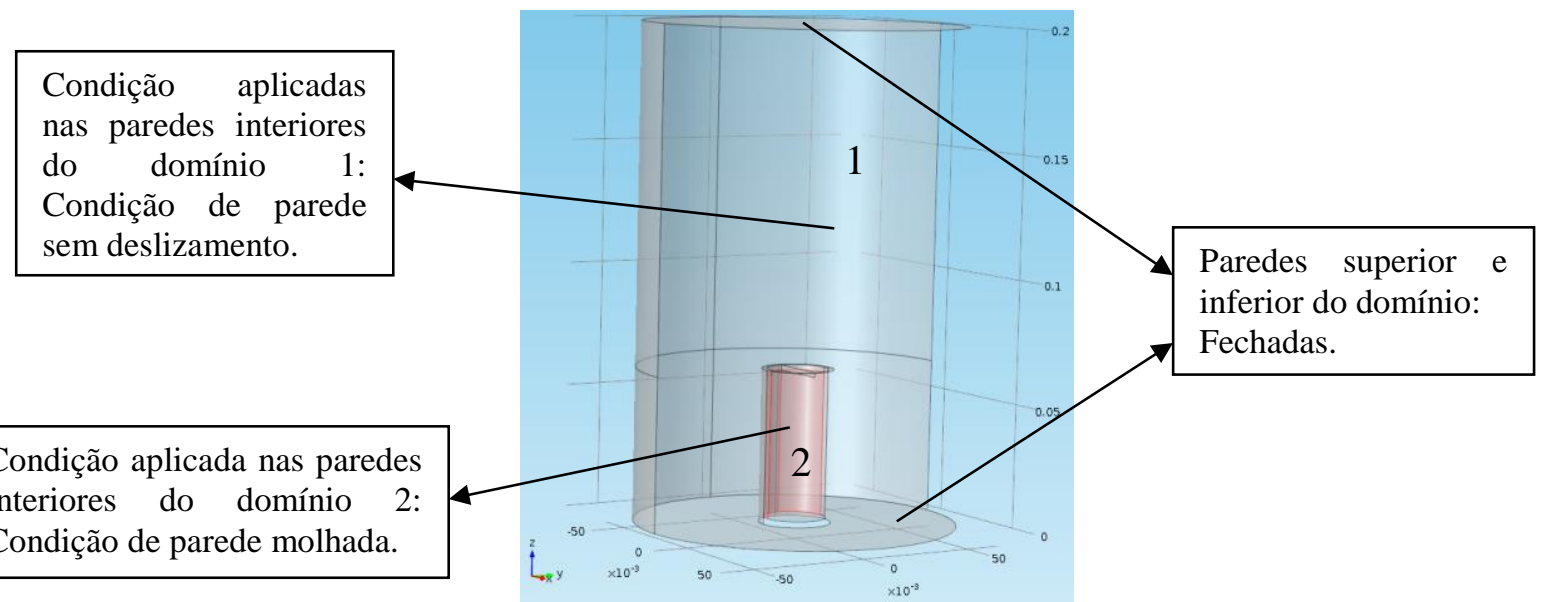

Figura 2 - Domínios e condições de contorno utilizadas na simulação.

A geometria criada trata-se de um modelo $3 \mathrm{D}$, composta por dois subdomínios. $\mathrm{O}$ subdomínio 1 corresponde ao recipiente que contem água destilada e o subdomínio 2 é referente ao frasco que inicialmente apresenta-se preenchido por óleo Spindura. Aplicou-se um perfil de pressão ao longo dos domínios e considerou-se que, inicialmente, o sistema está em repouso.

A malha construída para o domínio está apresentada na Figura 3. Foi definida como sendo uma malha estruturada fina, composta por 17553 elementos, sendo todos hexaédricos com qualidade média dos elementos de 0,74 .

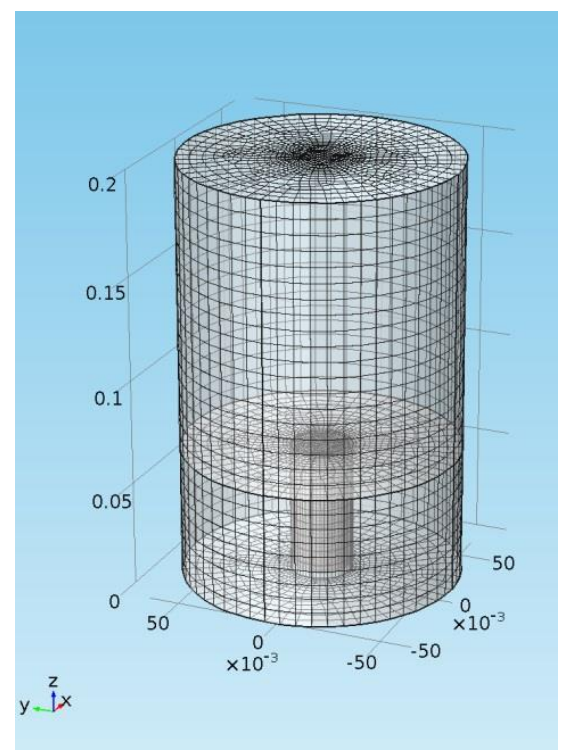

(a)

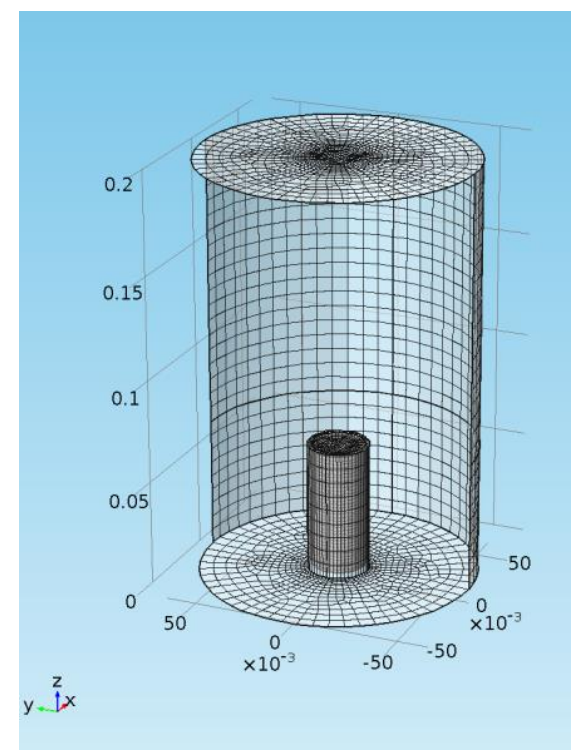

(b)

Figura 3 - Malha aplicada ao domínio. (a) Superfície exterior do cilindro. (b) Superfície interior e exterior. 


\section{RESULTADOS E DISCUSÃO}

A Figura 4 apresenta os resultados da simulação realizada com a malha estruturada hexaédrica mostrando a evolução do deslocamento do óleo pela água.

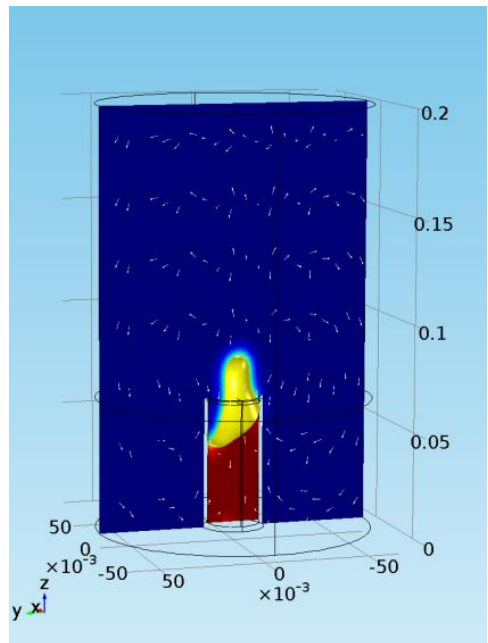

(a)

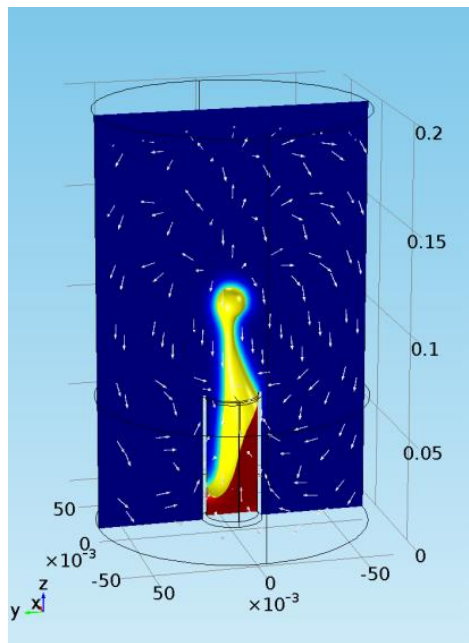

(b)

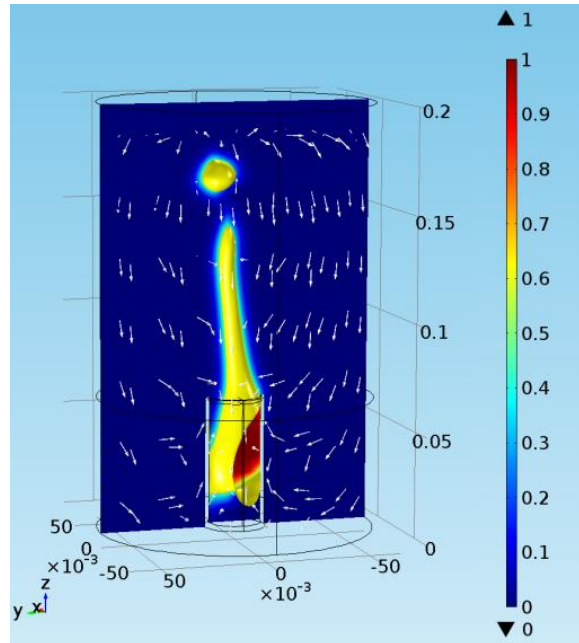

(c)

Figura 4 - Simulações de fração de volume. (a) Tempo de simulação 0,40 s. (b) Tempo de simulação 0,63 s. (c) Tempo de simulação 0,95 s.

A inversão de fases produz padrões geométricos similares a dedos (fenômeno da digitação viscosa) (Xu, 1998). Este fenômeno pode ser claramente observado na Figura 4, onde na fase inicial do vazamento, observou-se o aumento de volume no topo do finger de óleo, que acontece imediatamente antes do gotejamento do mesmo.

As cores, neste caso indicam a proporção da fração de massa em cada uma das fases, onde o vermelho escuro representa a fração volumétrica de $100 \%$ de óleo e a coloração azul escura $100 \%$ de água. A superfície amarela representa a interface e corresponde à fração volumétrica de $50 \%$ de óleo e $50 \%$ de água.

No modelo proposto por Ayub e Bentsen (1999) e citado por Mariano (2008), foi comprovado que diferentes áreas da base dos fingers são produzidas em função dos diferentes valores de densidade e viscosidade dos fluidos envolvidos. Pode-se observar na Figura 4 que a área da base do finger de óleo mostrou-se sempre maior do que o da água. Também, de acordo com os vetores de velocidade apresentados nessa figura, pode-se perceber o sentido que toma o escoamento, ou seja, o óleo após a formação do finger tende a subir pelo lado direito, a água por sua vez, tende a descer pelo lado esquerdo e isto faz com que a água ocupe a parte inferior do domínio 2, consequentemente expulsando o óleo.

Apesar do comportamento simulado se mostrar fisicamente coerente, houve um acentuado alongamento do finger e este comportamento não foi observado no procedimento experimental realizado, visto que a formação de gotas ocorria logo após o término do frasco que continha o óleo. 
A Figura 5 apresenta o resultado da simulação para os campos de velocidade simulados para três momentos distintos.

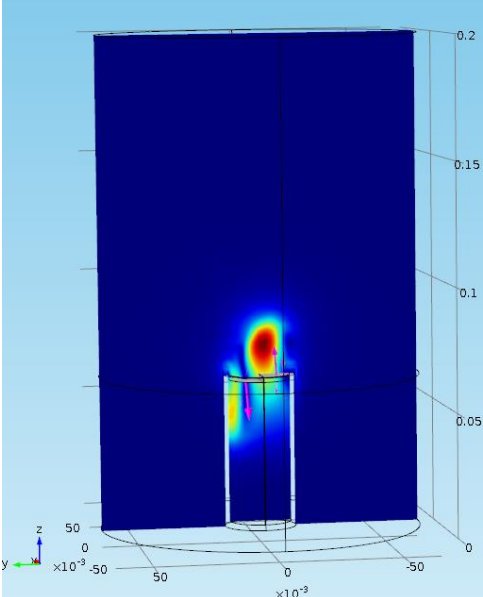

(a)

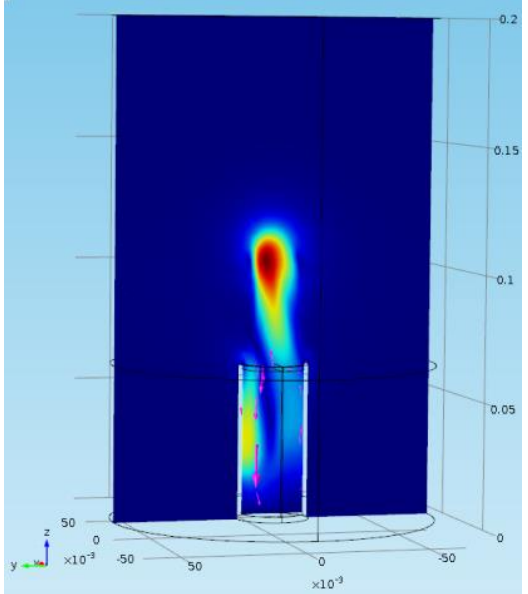

(b)

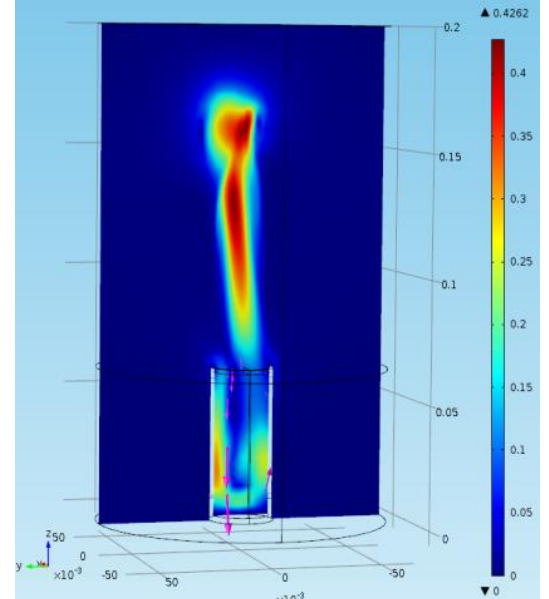

(c)

Figura 5 - Campos de velocidade simulados localizados em um plano diametral do domínio: (a) Tempo de 0,40 s; (b) Tempo de 0,63 s; (c) Tempo de 0,95 s.

A magnitude de velocidades é representada pelas cores, segundo a escala à direita; a cor vermelha está associada a velocidades maiores (valor máximo de $42,62 \mathrm{~cm} / \mathrm{s}$ ) e se apresenta na região superior e mediana do finger, enquanto a cor azul está associada às menores velocidades ou ao repouso da fase água no domínio.

Este é o comportamento esperado para este tipo de sistema, pois a força gravitacional frente à diferença de densidades das substâncias atua no sentido de promover o deslocamento do óleo pela água, fazendo com que o mesmo, que é menos denso, seja transportando para a parte superior do recipiente.

\section{CONCLUSÃO}

Com base no experimento e considerando as propriedades físicas e geométricas do sistema, conclui-se que o modelo, desenvolvido para simular o deslocamento de óleo inicialmente alojado no interior de um recipiente submerso em água, produziu resultados compatíveis com o arranjo e a natureza tridimensional do sistema.

Em linhas gerais, o modelo se mostrou adequado para descrever o fenômeno, permitindo colocar em evidência aspectos, tais como os campos de velocidades, que não podem ser observados diretamente no experimento, e uma interface definida que possibilita acompanhar o deslocamento da fase óleo em sua trajetória até a superfície da fase água.

O finger simulado se mostrou excessivamente alongado e a gota que se desprendeu do mesmo apresentou arestas ou não era tão arredondada quanto deveria. Por isso, faz-se ainda necessário um estudo de refinamento de malha, o que implica em maior custo computacional, além de um ajuste fino dos parâmetros utilizados na simulação. Estes aspectos devem ser considerados e aperfeiçoados, para que a simulação venha a reproduzir mais fielmente o 
comportamento observado no experimento.

\section{REFERENCIAS}

BAPTISTA, R. M.; QUADRI, M. B.; MACHADO, R. A. F.; BOLZAN, A.; NOGUEIRA, A.L.; LOPES, T. J.; MARIANO, G.C.. Effective Interfacial Tension And Geometrical Parameters Relationship For The Description Of Oil Leakages From Submarine Pipelines. $8^{o}$ Int. Conf. on Chem. \& Proc. Eng. v. 11, p. 401-406, 2007.

COMSOL Multiphysics 4.3b. COMSOL Documentation, Março 2014.

CORREIA, J.. Estudo da interface água/óleo no âmbito da indústria do petróleo com ênfase em software de simulação fluidodinâmica (CFD). 2009. 27 f. TCC (Graduação) - Curso de Engenharia Química, Universidade Federal de Santa Catarina, Florianópolis, 2009.

FELLER, R.. Estudo do vazamento e captura de óleo em ambiente subaquático. 2012. $112 \mathrm{f}$. Dissertação (Mestrado) - Curso de Engenharia Química, Universidade Federal de Santa Catarina, Florianópolis, 2012.

LAWRENCE, C.J.; HEWITT, G. F.. Laminar stratified pipe flow. Int. J. of Multip. Flow. v. 28, p. 963-996, 2002.

MARIANO, G. C.. Estudo do Escoamento Imiscível Água/Óleo Mediante Experimentação em Célula de Hele-Shaw e Simulação CFD. 2008. 102 f. Dissertação (Mestrado) Curso de Engenharia Química, Universidade Federal de Santa Catarina, Florianópolis, 2008.

OLIVEIRA, B. Y.; MARIANO G. C.; QUADRI, M.B.. Um estudo CFD de vazamento de óleo a partir de dutos submersos. COBEQ-IC, 2009.

SANTOS, R. G., Avaliação da molhabilidade de superfícies de oleodutos através de medidas de ângulo de contato: Efeito de asfaltenos e de ácidos naftênicos. 2003. $105 f$.

Dissertação (Mestrado)- Curso de Engenharia Química, Universidade Estadual de Campinas.

XU, J. J.; Interfacial wave theory of pattern formation. Berlin Heidelberg: Editora SpringerVerlag, 1998. 